\title{
Wastewater treatment and carbon trade: impact of certified emission reduction in a biogas project
}

\author{
R. Chamy ${ }^{1}, \mathrm{P}$. Reyes $^{2}$ \& E. Vivanco ${ }^{2}$ \\ ${ }^{1}$ Pontificia Universidad Católica de Valparaíso, NBC Center, Chile \\ ${ }^{2}$ CGFMDL, Chile
}

\begin{abstract}
Anaerobic digestion development has been marked by a constant evolution. Initially it was born as an efficient way to solve environmental problems, but later, a more comprehensive vision was adopted with the inclusion of the issues of biogas, bio-solids and irrigation water utilization. Later on, energy issues started being more relevant and to gain strength. Currently, a new concept has been included as a fundamental variable in environmental processes, namely, the reduction of greenhouse gases. In fact, the regulated/voluntary carbon market has a diversity of developing projects that otherwise would not be possible to be developed. In other words, anaerobic digestion must be viewed as a technology that must be thought about from a systemic viewpoint, where not only a contribution to the waste problem is made, but in addition, a contribution is made to the Planet's environmental and energy sustainability. In this work a new systemic approach for biogas projects is shown. How the carbon market can help to solve environmental and energetic problems, especially in under developed countries. Finally, a real project is described as an example in order to validate this approach.

Keywords: emission sources, biogas, carbon trade, greenhouse gases, anaerobic digestion, carbon market.
\end{abstract}

\section{Introduction}

From the first IPCC 1992 report during the Earth's Summit organized in Rio de Janeiro, the United Nations Framework Convention against Climate Change (UNFCCC) was created in order to stabilize the greenhouse gases (GHGs) 
emissions caused by man. In turn, the UNFCCC work took to the Kyoto Protocol in 1997 that is an instrument through which goals are established to reduce the emissions of GHGs in industrialized countries.

This protocol has three mechanisms to face this hard task; the joint implementation, emissions trading and clean development mechanism (CDM) [1]. Industrialized countries can only carry out the two first mechanisms, while the clean development mechanism aims to achieve sustainable development and assisting industrialized countries in the fulfilment of their commitments.

Since 2005, the carbon market has grown substantially, achieving a reduction of 315,668,272 tons $\mathrm{CO}_{2}$ /year at worldwide level, with 2,233 registered projects and some other projects in their registration and validation processes. Within this general context, Chile is one of the top ten countries in terms of project registration and ranks as the second country if the technologies that are being implemented are considered [2].

From the beginning, biogas projects have been one of the pillars of development in issues related to climate change, mainly due to the methane capacity as a greenhouse gas that is twenty one times higher than the $\mathrm{CO}_{2}$ capacity and due to the fact that its capture can be made in a relatively simple manner in the most common industrial processes where, for example, it is produced in residential waste landfills, water and solids treatment processes and in general, in organic matter decomposition processes.

In fact, it has been established that climate is a consequence of the interaction between the atmosphere, the oceans, ice layers (cryosphere), living organisms (biosphere) and soils, sediments and rocks (geosphere) [3]. These components that make up the climate system must be in balance, so any factor that influences it at global scale must be considered as the agent that causes global change.

For the development of CDM projects there are several steps, called CDM cycle $[2,4]$. The first step starts with a determination of whether the project concept would qualify as a CDM project, including screening against project criteria, estimating the magnitude of emissions reductions, and preparing a Project Design Document (PDD) to meet certain specifications. The PDD must address the following key issues [5]:

i. Establishing the "baseline" for the project, this represents the anthropogenic emissions that would occur in the absence of the proposed project activity.

ii. Demonstrating "additionality," which in essence is a demonstration that the proposed project is not "business as usual." This allows that environmental projects can be executed due to CDM.

iii. A monitoring methodology that effectively addresses gas flow and composition. It consists of tracking and recording the project leader should emissions of greenhouse gases are reduced and/or capture. Such monitoring should be made according to previously defined monitoring plan in project formulation and validated by a Designated Operational Entity (DOE). 
According to the procedures established by the UNFCCC [2], the project also needs a letter issued by the Designated National Authority (DNA) which should confirm that the project contributes to sustainable development of the country. The next step is the validation conducted by a DOE accredited by the Executive Board (EB) of the United Nations, which consists of a project evaluation to determine whether it complies with the requirements set by international bodies for projects under the CDM.

The register is the formal acceptance by the EB of a validated project as a CDM project conducted by the DOE process. Then, the project proponents are responsible for implementing the project, to be implemented as stipulated in the PDD.

Finally, the verification involves regular review of the calculations and procedures done by the project leader to quantify their reductions of greenhouse gases. Such review or verification is performed by a DOE that may or may not be the same as previously performed the project validation, depending on whether the project is large or small scale. Once the operational entity has been found that the quantification of greenhouse gases reductions is correct, the EB proceed to the certification of these quantities, expressed as Certified Emission Reductions (CERs).

\section{A systemic viewpoint for industrial effluents treatment}

Is well known the benefits of anaerobic digestion, which under adequate conditions not only can stabilize wastes, control odours and produce mineralize nutrients, also is a net energy producer and minimizes environmental impact from waste emissions, in special avoid the atmospheric emissions of $\mathrm{CH}_{4}$, one of the most important GHGs [6].

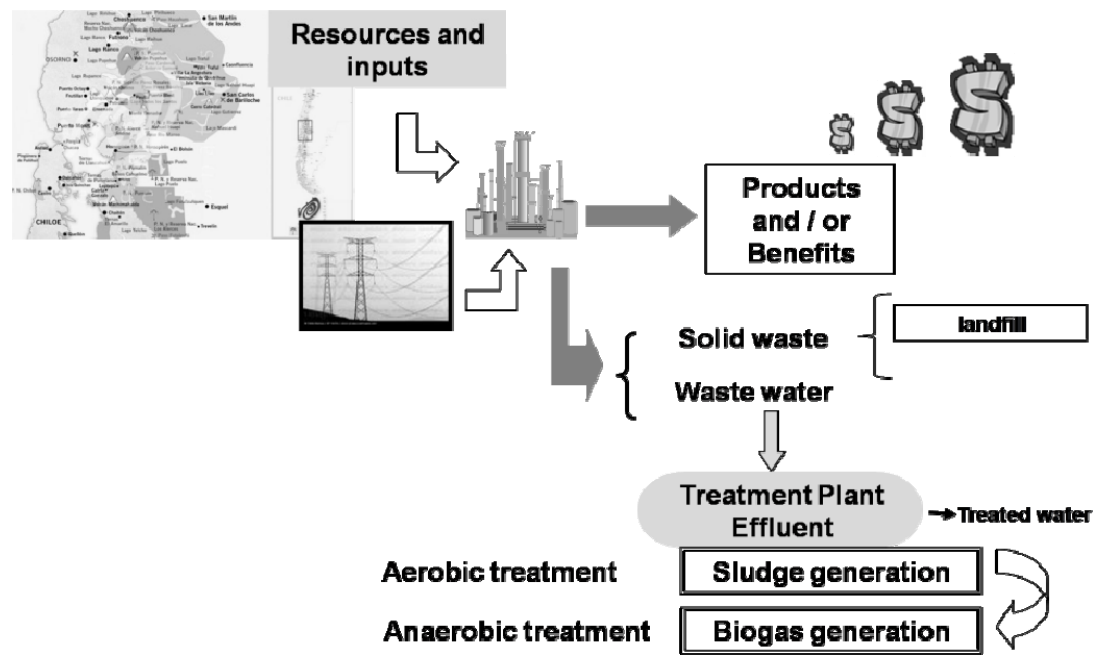

Figure 1: Traditional approach for an environmental solution for the industry. 
In a new vision, anaerobic digestion has to be seen in a systemic viewpoint. If an industry needs to solve an environmental problem with its effluents, the solution is not only a treatment plant; the solution is an integrated project in which the economic, energetic and environmental sustainability are important, not only for the industry, also for the region and the planet.

The traditional and the proposal systemic and integrated approach are shown in the Figures 1 and 2. In the first case, the environmental problem is solved, but in Figure 2, the energetic and GHGs reduction are considered in the overall solution of the problem.

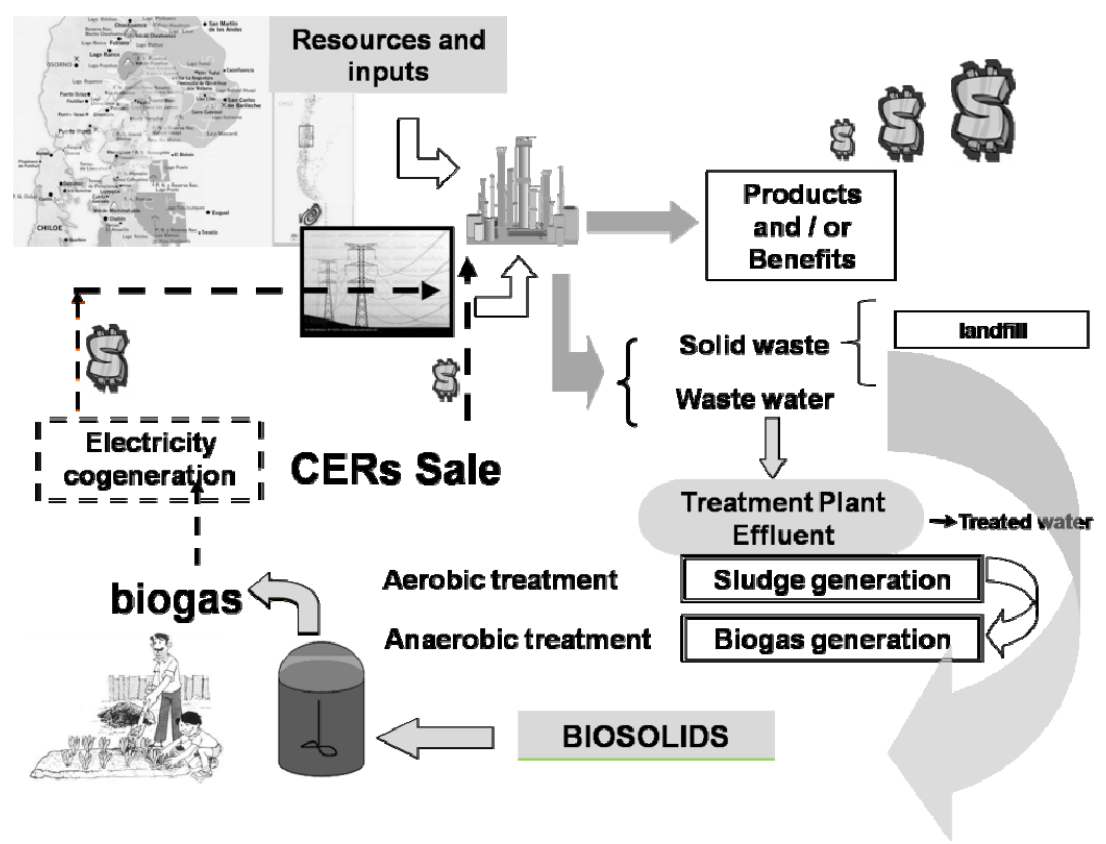

Figure 2: $\quad$ Systemic approach for an environmental solution for the industry.

In industrializes countries, the solution isn't easy but is possible. Subsidies, special fees, fixed and guaranties prices for the energy are incentives for these types of projects. In the other hand, under develop countries didn't have this kind of helps for these projects. The Kyoto Protocol is a way in which, through the carbon market, rich countries contribute to the environmental development of poor countries.

Currently, $14 \%$ of the registered projects at worldwide level correspond to projects related to anaerobically digested biogas [2]. As a whole, these projects decrease 9.5 million tons of $\mathrm{CO}_{2}$, and the main countries that develop these projects are Mexico, Brazil, Philippines and Malaysia [2]. The projects that have been developed mainly correspond to liquid effluent treatment and livestock raising waste treatment. However, there are more possibilities that the framework convention establishes because its methodological panel has established other 
possibilities that allow determining the GHGs produced under different circumstances. Table 1 presents a summary of the methodologies applicable to CDM projects [2].

Table 1: Methodologies description that can be applied to anaerobic digestion projects.

\begin{tabular}{|c|c|}
\hline Methodology Number & Methodology Title \\
\hline ACM $^{*} 0002$ & $\begin{array}{c}\text { Consolidated methodology for grid- } \\
\text { connected electricity generation from } \\
\text { renewable sources }\end{array}$ \\
\hline ACM0003 & $\begin{array}{c}\text { Emissions reduction through partial } \\
\text { substitution of fossil fuels with } \\
\text { alternative fuels or less carbon } \\
\text { intensive fuels in cement manufacture }\end{array}$ \\
\hline ACM0010 & $\begin{array}{c}\text { Consolidated methodology for GHGs } \\
\text { emission reductions from manure } \\
\text { management systems }\end{array}$ \\
\hline ACM0014 & $\begin{array}{c}\text { Mitigation of greenhouse gas } \\
\text { emissions from treatment of industrial } \\
\text { wastewater }\end{array}$ \\
\hline AM**0025 & $\begin{array}{c}\text { Avoided emissions from organic } \\
\text { waste through alternative waste } \\
\text { treatment processes }\end{array}$ \\
\hline AMS***-III.H. & Methane recovery in wastewater \\
& treatment \\
\hline
\end{tabular}

*Approved methodology

**Approved consolidated methodology

***Approved small scale methodology

These methodologies can be concretely applied to anaerobic digestion projects; however, anaerobic digesters can be used in other types of projects through the use of biogas as fuel for electrical or thermal energy generation. Table 2 shows the methodologies that can be applied to biogas projects.

Table 2: $\quad$ Other methodologies that can be applied to biogas projects.

\begin{tabular}{|c|c|}
\hline Methodology Number & Description \\
\hline AM36 & $\begin{array}{c}\text { Fuel switch from fossil fuels to biomass residues in } \\
\text { boilers for heat generation }\end{array}$ \\
\hline ACM2 & $\begin{array}{c}\text { Grid-connected electricity generation for renewable } \\
\text { sources (no biomass) }\end{array}$ \\
\hline ACM6 & Grid-connected electricity from biomass residues \\
\hline AMS-I.C. & Thermal energy for the user with or without energy \\
\hline AMS-I.D. & Grid-connected renewable energy connection \\
\hline AMS-III.E & $\begin{array}{c}\text { Avoidance of methane production from decay of } \\
\text { biomass through controlled combustion, gasification or } \\
\text { mechanical/thermal treatment }\end{array}$ \\
\hline
\end{tabular}


The reduction of GHGs is certified in equivalent tons of $\mathrm{CO}_{2}$ through CERs that are determined by means of the $\mathrm{CO}_{2}$ equivalence that the different gases established in the Kyoto Protocol have [1]. The equivalences of each one of the gases are shown in table 3 .

Table 3: Equivalences among the different greenhouse gases established in the Kyoto Protocol at equivalent $\mathrm{CO}_{2}$.

\begin{tabular}{|c|c|c|}
\hline Compound & Formula & $\mathrm{CO}_{2}$ equivalence \\
\hline Carbon Dioxide & $\mathrm{CO}_{2}$ & 1 \\
\hline Methane & $\mathrm{CH}_{4}$ & 21 \\
\hline Nitrous Oxide & $\mathrm{N}_{2} \mathrm{O}$ & 310 \\
\hline Hydrofluorocarbons & $\mathrm{HFC}$ & 740 \\
\hline Perfluorocarbons & $\mathrm{PFC}$ & 1,300 \\
\hline Sulphur Hexafluoride & $\mathrm{SF}_{6}$ & 23,900 \\
\hline
\end{tabular}

One thousand tons of $\mathrm{CO}_{2 \mathrm{e}}$ per year can be easily achievable by an anaerobic digestion project, because of is enough to generate 48 tons of methane equivalents to 80 tons of biogas to achieve such amount [7]. Currently, each one of the emission certificates has a market value of $€ 14$, and this implies that a project that tries to solve an environmental problem in a company, if it is carried out correctly, could transform itself from a project that generates additional costs into a project with unimaginable economic benefits.

This is because medium sized projects that use biodigesters would be generating approximately 5,000 CERs that would generate additional profits for the project developer. It must be underlined that the CDM benefits are not enough to fully finance the project; however, they could partially cover part of the project or could provide the profitability that is missing to make the decision to go forward with it.

\section{A case study for methodology application}

In this work a biogas project for a vertically turkey industry is shown. In this project the identification, quantification and characterization of the principal waste generated by the poultry industry was carried out [8], with the aim of determining the energy potential it may possess in order to solve its environmental problem with energy generation and with an adequate financing with carbon credits. As was mention before, the baseline is fundamental in order to write the PDD document.

Unlike other countries, Chile's production processes are organized vertically, that is, the company which breeds the birds is the same one that slaughters and processes the animals. This means that one company generates a variety of waste, which can generally be accessed within a small area, allowing the viable development of a stabilization technology with energy generation, since this energy can be consumed by the company itself without the necessity of selling it to other company. In fact, the greater part of the waste is generated in the breeding stage, while the greater part of the energy is consumed during the 
slaughter and processing stages. This has been one of the main problems impeding the development of these systems on a global scale, since these processes are not organised vertically; the energy generator isn't always able to consume the energy itself. This brings other problems such as calculating a price for energy selling and finding markets interested in acquiring it.

Biogas production was proposed for the stabilization of these waste products, which is based on the transformation of organic matter via its degradation into a biogas, $\mathrm{CH}_{4}$ and $\mathrm{CO}_{2}$. This biogas may then be collected and used as fuel.

Though, currently there exists some digestion processes in Chile for solid waste via anaerobic digestion, the majority of this energy is currently lost or it is produced at a very low proportion to the amount consumed. CDM gives incentives for the development of new technologies that have generated a new landscape in which production of electrical energy from biogas generated from the stabilization of solids is seen as a valid alternative.

From this study it may be concluded that there is a large potential for the methanisation of waste products generated by the poultry processing industry.

This is due to energetic utilization of biogas produced and for the CERs obtained. An economic feasibility with and without carbon credits were carried out. The total investment for the project was $€ 9.500 .000$ and is it possible to obtain in CERs around $€ 400.000$ per year. Without credits carbon the project was not possible, perhaps with the CERs sale the RIR was $15.3 \%$.

Recent studies [7-10] estimate that the total potential energy generation from poultry manure corresponds to approximately $169 \mathrm{MW}$ of installed capacity and can generated $€ 100.000 .000$ of CERs. The use of the electrical energy generation potential and carbon credits from anaerobic co-digestion of the principal waste products would not only mean a solution to an environmental and sanitary problem meaning the disposal of this waste, but moreover, an important business opportunity.

\section{Conclusions}

Biogas must be part of the society's response to the challenge of reverting climate change problems. Anaerobic digestion reduces the GHGs in two ways. The first, and the most important, by capturing biogas, and the second, anaerobic digestion produces biogas to replace fossil fuels. So, anaerobic digestion is a flexible technology being applicable in different scale, and permits to make a society more resource efficient supporting economic grow for under develop countries and improving quality of life for all.

The systemic approach shown in this work, permits to develop more ambitious anaerobic projects in under develop countries by considering GHGs reduction as a fundamental variable. With this mechanism, industrialised countries helps to the development of poor countries and can obtain its reduction goals. 


\section{References}

[1] Kyoto Protocol to the United Nations Framework Convention on Climate Change, United Nations, 1998. www.unfecc.int/resource/docs/ convkp/kpeng.pdf

[2] UNFCCC, www.unfecc.int

[3] Houghton, J. T., Jenkins, G. J. \& Ephraums, J. J., (eds). Climate Change: The IPCC Scientific Assessment, Cambridge University Press: Cambridge, New York and Melbourne, 1990.

[4] Fenhann, J. \& Hinostroza, M., CDM Information and Guidebook, UNEP Risoe Centre on Energy, Climate and Sustainable Development National Laboratory for Sustainable Energy: Denmark, pp. 29-59, 2011.

[5] Fenhann, J. \& Hinostroza, M., CDM Information and Guidebook, UNEP Risoe Centre on Energy, Climate and Sustainable Development National Laboratory for Sustainable Energy: Denmark, pp. 59-79, 2011.

[6] Grady, C. P. L., Daigger, G., Love, N. \& Filipe, C., Anaerobic Processes (Chapter 14). Biological Wastewater Treatment, ed. CRC Press: Boca Raton, London and New York, pp. 561-616, 2011.

[7] Chamy, R. \& Vivanco, E., Potencial de Biogas, Comisión Nacional de Energía (CNE) \& Deutsche Gesellschaft für Technische Zusammenarbeir (GTZ) GmbH: Chile, pp. 65-73, 2007.

[8] Chamy, R. \& Ramos, C., Factors in the determination of methanogenic potential of manure. Bioresource Technology, 102(17), pp. 7673-7677, 2011.

[9] Chamy, R., Vivanco, E. \& Ramos, C., Anaerobic mono-digestion of turkey manure: efficient revaluation to obtain methane and soil conditioner, Journal of Water Resource and Protection, 3(8), pp. 584-589, 2011.

[10] Chamy, R., León, C., Vivanco, E., Poirrier, P. \& Ramos, C., Anaerobic monodigestion of poultry manure: determination of operational parameters for CSTR. Water Science \& Technology, 65(1), pp. 53-59, 2011. 